\title{
Bcl2110 mediates the proliferation, invasion and migration of ovarian cancer cells
}

\author{
SU-YEON LEE, JINIE KWON, JI HYE WOO, KYEOUNG-HWA KIM and KYUNG-AH LEE \\ Department of Biomedical Sciences, College of Life Sciences, CHA University, \\ Seongnam-si, Gyeonggi-do 13488, Republic of Korea
}

Received July 18, 2019; Accepted December 2, 2019

DOI: $10.3892 /$ ijo.2019.4949

\begin{abstract}
Bcl2110, also known as Diva, Bcl-b and Boo, is a member of the $\mathrm{Bcl} 2$ family of proteins, which are involved in signaling pathways that regulate cell apoptosis and autophagy. Previously, it was demonstrated that $\mathrm{Bcl} 2110$ plays a crucial role in the completion of oocyte meiosis and is a key regulator of Aurora kinase A (Aurka) expression and activity in oocytes. Aurka is overexpressed in several types of solid tumors and has been considered a target of cancer therapy. Based on these previous results, in the present study, the authors aimed to investigate the regulatory role of $\mathrm{Bcl} 2110$ in A2780 and SKOV3 human ovarian cancer cells. The protein expression of $\mathrm{Bcl} 2110$ was examined in human cancer tissues and cell lines, including the ovaries, using a tissue microarray and various human ovarian cancer cell lines. It was found that $\mathrm{Bcl} 2110$ regulated the protein stability and activities of Aurka in ovarian cancer cells. Although apoptosis was not affected, the cell cycle was arrested at the G0/G1 phase by Bcl2110 knockdown. Of note, cell viability and motility were markedly increased by Bcl 2110 knockdown. On the whole, the findings of this study suggest that $\mathrm{Bcl} 2110$ functions as tumor suppressor gene in ovarian cancer.
\end{abstract}

\section{Introduction}

Bcl2110, also known as Diva, Bcl-b or Boo, is a member of the Bcl-2 family of proteins, which are central mediators of apoptosis and autophagy $(1,2)$. The Bcl-2 family proteins contain up to 4 conserved amino acid sequences, known as Bcl-2

Correspondence to: Professor Kyung-Ah Lee, Department of Biomedical Sciences, College of Life Sciences, CHA University, 335 Pangyo-ro, Bundang-gu, Seongnam-si, Gyeonggi-do 13488, Republic of Korea

E-mail: leeka@cha.ac.kr

Abbreviations: AURKA, Aurora kinase A; BH, Bcl-2 homology; RNAi, RNA interference; siRNA, small-interfering RNA; Tpx2, targeting protein for xenopus kinesin-like protein 2

Key words: Bcl2110, Aurka, ovarian cancer, cell proliferation, migration, invasion homology $(\mathrm{BH})$ domains $(1,3)$. These proteins are grouped into 3 categories: i) Anti-apoptotic proteins, including Bcl-2, Bcl-xL, Bcl-w, NR-13, A1 and Mcl-1; ii) multi-domain pro-apoptotic proteins, such as Bax, and Bak; and iii) $\mathrm{BH} 3$ domain-only proteins, such as Bad, Bim, Bid and Bik $(1,4)$. Interactions between pro-apoptotic and anti-apoptotic $\mathrm{Bcl}-2$ family proteins play important roles in controlling and promoting apoptosis $(1,3)$. However, $\mathrm{Bcl} 2110$ reportedly has contradictory functions in different apoptotic cells or tissues and is recognized for its both pro-apoptotic (5-7) and anti-apoptotic activities (8-10).

Previously, it was reported that $\mathrm{Bcl} 2110$ was highly expressed in mouse ovaries and oocytes and that it was associated with cytoskeletal proteins $(11,12)$. It was demonstrated that Bcl2110-depleted oocytes arrested at the metaphase I stage, exhibiting abnormal spindle and chromosome formation (12). These results revealed that $\mathrm{Bcl} 2110$ plays a crucial role in oocyte meiosis. By using microarray analysis, it was found that $\mathrm{Bcl} 2110$ was associated with cytoskeletal proteins, such as targeting protein for xenopus kinesin-like protein 2 (Tpx2) and centrosomal protein of $192 \mathrm{kDa}$ (Cep192), which are well-known cofactors of Aurora kinase A (Aurka) (13). Notably, Bcl2110 was subsequently demonstrated to directly interact with Tpx 2 in meiotic spindles and to further regulate the expression and activity of Aurka (14).

In somatic cells, Tpx 2 directly interacts with Aurka at spindle microtubules and protects Aurka from degradation (15-17). Aurka controls multiple aspects of mitotic cell division and plays important roles in centrosome maturation and bipolar spindle formation in somatic cells (18). Aurka expression and activity are upregulated in several types of solid tumors. Additionally, Aurka overexpression has been shown to increase cancer cell malignancy (19-22), promptly impair cell cycle progression and cause chromosomal instability, supernumerary centrosomes and multipolar spindles. These properties have led to the consideration of Aurka as an oncogene and a target of cancer therapy (23-25). Based on our previous finding that $\mathrm{Bcl} 2110$ is an upstream regulator of Aurka and considering that Aurka is considered a crucial oncogenic factor (14), it was hypothesized that $\mathrm{Bcl} 2110$ plays an important role in cancer cells. If $\mathrm{Bcl} 2110$ is functionally connected with Aurka in cancer cells, Bcl2110 may be a novel effective therapeutic target that can be used with Aurka inhibitors as an anticancer drug. 
The functions of Bcl2110 in cancers have been previously reported. $\mathrm{Bcl} 2110$ plays roles as an oncogene and as a tumor suppressor gene depending on the type of cancer. In gastric and lung cancer cells, Bcl2110 exhibits a low-level expression relative to its expression in adjacent normal tissues, and the overexpression of $\mathrm{Bcl} 2110$ induces apoptosis and cell growth inhibition (26-29). By contrast, Bcl2110 acts as an oncogene in myelodysplastic syndromes (MDS), acute myeloid leukemia (AML), glioma and breast cancers $(9,30,31)$. However, although $\mathrm{Bcl} 2110$ is highly expressed in human ovaries, the biological functions of $\mathrm{Bcl} 2110$ in ovarian cancer have yet to be reported. Therefore, the aims of this study were to determine whether Bcl2110 regulates Aurka and to investigate the function of Bcl2110 in A2780 and SKOV3 ovarian cancer cells.

\section{Materials and methods}

Tissue microarray. Slides including 20 different types of human cancer tissues (brain, esophagus, larynx, thymus, thyroid, breast, stomach, pancreas, tongue, lung, lymph node, liver, kidney, ovary, cervix, testis, colon, rectum, skin and soft tissue) were purchased from AccuMax (ISU ABXIS). Slides made from formalin-fixed, paraffin-embedded blocks and stained with hematoxylin and eosin were used to define the most morphologically representative, well-fixed cells. Single-tissue cores ( $1 \mathrm{~mm}$ in diameter) were sampled from each paraffin block and assembled into a recipient paraffin block using a tissue microarray instrument (AccuMax Array, ISU ABXIS). To detect $\mathrm{Bcl} 2110$ in cancer tissues, immunohistochemical staining was performed with an anti-Bcl2110 antibody. Briefly, antigen retrieval was conducted by boiling the slide in $1 \mathrm{X}$ citrate buffer for $10 \mathrm{~min}$, and blocking was then performed in hydrogen peroxide solution for $10 \mathrm{~min}$. The slide was incubated with the anti-Bcl2110 antibody (anti-BCL2L10, 1:100 dilution, ab151419, Abcam) for $1 \mathrm{~h}$ at room temperature and incubated with a horseradish peroxidase (HRP) polymer solution (Lab Vision; Thermo Fisher Scientific) for $15 \mathrm{~min}$. Thereafter, the slide was stained with a 3,3'-diaminobenzidine-tetrahydrochloride (DAB) solution (Vector Laboratories) at room temperature for $3 \mathrm{~min}$ and counterstained with hematoxylin (Sigma-Aldrich; Merck KGaA) for $5 \mathrm{~min}$.

Cells and cell culture. Six ovarian cancer cell lines were used in this study. The CAOV-3, SKOV3 and OVCAR-3 cells were obtained from the Korean Cell Line Bank and the COV-318, A2780 cells were obtained from Cellbank Australia; the TOV-21G cell line was purchased from ATCC and the normal ovarian epithelia cell line, HOSE, was purchased from Innoprot. The CAOV-3 and COV-318 cells were maintained in DMEM (Gibco; Thermo Fisher Scientific) containing $10 \%$ fetal bovine serum (FBS); the SKOV3 and OVCAR-3 cells were maintained in RPMI-1640 (Gibco; Thermo Fisher Scientific) containing 10\% FBS, 25 mM HEPES (Gibco; Thermo Fisher Scientific), 25 mM NaHCO 3 (Sigma-Aldrich; Merck KGaA); the TOV-21G cells were maintained in MCDB and Medium 199 containing $15 \%$ FBS; the A2780 cells were maintained in RPMI-1640 containing 10\% FBS; HOSE was maintained in medium provided from Innoprot.
Cell transfection. Bc12110 small-interfering RNA (siRNA) was synthesized by Shanghai GenePharma Co., Ltd. and negative control siRNA was purchased at Bioneer. One day prior to transfection, the A2780 and SKOV3 cancer cells were seeded in 6-well plates. Before transfection, the medium was removed and replaced with $1.5 \mathrm{ml}$ of fresh growth medium. All siRNAs were diluted in $0.25 \mathrm{ml}$ of OPTI-MEM to a final concentration of $100 \mathrm{nM}$, and Lipofectamine 3000 (Invitrogen; Thermo Fisher Scientific) was diluted in $0.25 \mathrm{ml}$ of OPTI-MEM. The solutions were incubated individually for $5 \mathrm{~min}$ at room temperature and then combined and incubated for an additional $20 \mathrm{~min}$ at room temperature. The mixture was then added to each well containing cells, which were maintained in a $5 \% \mathrm{CO}_{2}$ atmosphere at $37^{\circ} \mathrm{C}$ for $48 \mathrm{~h}$.

Total RNA extraction and cDNA synthesis. After the cultured cells were washed twice with PBS, $1 \mathrm{ml}$ of TRIzol reagent (Takara Bio) and $0.2 \mathrm{ml}$ of chloroform were added, and the mixture was incubated at room temperature for $10 \mathrm{~min}$. The cells were centrifuged at $12,000 \mathrm{x}$ g for $20 \mathrm{~min}$ at $4^{\circ} \mathrm{C}$, and the supernatants were transferred to new tubes and resuspended in $0.5 \mathrm{ml}$ of isopropanol. After the tubes were centrifuged at $12,000 \mathrm{x} \mathrm{g}$ for $10 \mathrm{~min}$ at $4^{\circ} \mathrm{C}$, the supernatants were discarded, and the precipitates were dried. The pellets were washed with $75 \%$ ethanol, dried, and dissolved in $0.1 \%$ diethylpyrocarbonate (DEPC)-treated water. To synthesize first-strand cDNA, total RNA $(2 \mu \mathrm{g})$ was added to DNase I (New England Biolabs) and DNase I buffer (New England Biolabs), and the total volume was adjusted to $11 \mathrm{ml}$ with DEPC-treated water. The mixture was incubated at room temperature for $15 \mathrm{~min}, 1 \mathrm{ml}$ of $25 \mathrm{mM}$ EDTA were added, and the mixture was incubated at $65^{\circ} \mathrm{C}$ for $15 \mathrm{~min}$. Subsequently, $1 \mathrm{ml}$ of oligo dT was added, and the mixture was incubated at $70^{\circ} \mathrm{C}$ for $10 \mathrm{~min}$. M-MLV RNase (Promega), $5 \mathrm{X}$ buffer (Promega), RNase inhibitor (Promega) and $10 \mathrm{mM}$ dNTP were then added, and the reaction was performed at $42^{\circ} \mathrm{C}$ for $1 \mathrm{~h}$ and $94^{\circ} \mathrm{C}$ for $2 \mathrm{~min}$.

Western blot analysis. Proteins were extracted from the treated cells using RIPA lysis buffer with a $1 \%$ protease inhibitor cocktail (Thermo Fisher Scientific) and $0.5 \mathrm{M}$ EDTA ( $\mathrm{pH}$ 8.0). Protein concentrations were estimated using the Bio-Rad protein assay reagent (Bio-Rad) according to the manufacturer's instructions. Protein extracts $(30 \mu \mathrm{g})$ were separated using 10\% SDS-PAGE and then transferred onto PVDF membranes (Amersham Biosciences). The membranes were blocked for $1 \mathrm{~h}$ in Tris-buffered saline/Tween [TBST; $0.2 \mathrm{M} \mathrm{NaCl}, 0.1 \%$ Tween-20, and $10 \mathrm{mM}$ Tris ( $\mathrm{pH} 7.4$ )] containing $5 \%$ non-fat dry milk. Immunoblots were incubated overnight at $4^{\circ} \mathrm{C}$ with diluted polyclonal antibodies against Bcl2110 (\#3869S, Cell Signaling Technology), Aurka (\#610939, BD Biosciences), cyclin-dependent kinase (CDK)4 (sc-23896, Santa Cruz Biotechnology), cyclinD1 (\#2978S, Cell Signaling Technology), p27 (\#2552S, Cell Signaling Technology), p21 (sc-6246, Santa Cruz Biotechnology), p16 (\#80772S, Cell Signaling Technology) and $\beta$-actin (PA1-183, Invitrogen; Thermo Fisher Scientific) diluted 1:1,000, washed several times with TBST and incubated with diluted solutions of goat anti-rabbit IgG (\#65-6120, Thermo Fisher Scientific) or goat anti-mouse IgG (\#62-6520, Thermo Fisher Scientific) 
diluted 1:2,000 for $1 \mathrm{~h}$ at room temperature. After each step, the membranes were washed several times with TBST, and the relative expression of the protein bands was quantified using the chemiDoc XRS+ imaging system with Image Lab software.

Immunofluorescence staining. The cells were seeded at density of $1 \times 10^{5}$ onto cover slides and incubated at $5 \% \mathrm{CO}_{2}$ and $37^{\circ} \mathrm{C}$. After $24 \mathrm{~h}$, the medium was removed from the dish, and prewarmed $\left(37^{\circ} \mathrm{C}\right)$ staining solution containing $100 \mathrm{nM}$ MitoTracker (Invitrogen; Thermo Fisher Scientific) stain was added. The cells were then incubated for $15 \mathrm{~min}$ at $37^{\circ} \mathrm{C}$, fixed with $4 \%$ formaldehyde (Electron Microscopy Sciences) in medium for $20 \mathrm{~min}$, and permeabilized with $0.2 \%$ Triton $\mathrm{X}-100$ (Sigma-Aldrich; Merck KGaA) in PBS for $20 \mathrm{~min}$. The cells were then washed 3 times with PBS, blocked with $3 \%$ bovine serum albumin in PBS for $1 \mathrm{~h}$, and incubated overnight at $4^{\circ} \mathrm{C}$ with a primary antibody against $\operatorname{Bcl} 2110$ (1:100; \#3869S, Cell Signaling Technology). The cells were washed 3 times with PBS and then incubated with Alexa Fluor 488-conjugated anti-rabbit IgG (1:100; \#A11034 Invitrogen; Thermo Fisher Scientific). Nuclei were stained with 4',6-diamidino-2-phenylindole (DAPI) (Invitrogen; Thermo Fisher Scientific) at room temperature for $10 \mathrm{~min}$, and the samples were then coverslipped with mounting solution (Dako). Observations were performed under a confocal microscope (Leica).

Measurement of Aurka activity. Following transfection with Bcl2110 siRNA, Aurka activity was measured using the CycLex ${ }^{\circledR}$ Aurora-A Kinase Assay/Inhibitor Screening kit (\#CY-1165; MBL). According to protocols provided by the manufacturer of this kit, cytoplasmic and nuclear extracts were preferentially separated from whole cell lysates using the Subcellular Protein Fraction kit (\#78840; Thermo Fisher Scientific). Each cell lysate was used to measure Aurka activity according to manufacturer's instruction.

Cycloheximide decay assay. Following siRNA transfection for $48 \mathrm{~h}, 50 \mu \mathrm{g} / \mathrm{ml}$ cycloheximide (Sigma-Aldrich; Merck KGaA) was added to inhibit de novo protein synthesis. The cells were then harvested at each indicated time point $(0,30,60,90$, 120 and $150 \mathrm{~min}$ ) and subjected to western blot analysis as described above.

Cell apoptosis assay. Apoptosis was evaluated by Annexin Vfluorescein isothiocyanate (Annexin V-FITC) and propidium iodide (PI) staining in transfected cells using an Annexin VFITC Apoptosis Detection kit (BD Biosciences) according to the manufacturer's instructions. The cells were harvested at $48 \mathrm{~h}$ after transfection. Cell pellets were washed twice with PBS and suspended in $100 \mathrm{ml}$ of $1 \mathrm{X}$ binding buffer $(10 \mathrm{mM}$ HEPES/NaOH, $140 \mathrm{mM} \mathrm{NaCl}, 25 \mathrm{mM} \mathrm{CaCl}_{2}, \mathrm{pH}$ 7.4). The cells were then incubated with $5 \mathrm{ml}$ of Annexin V-FITC and $10 \mathrm{ml}$ of PI at room temperature for $15 \mathrm{~min}$ in the dark. Following incubation, $400 \mathrm{ml}$ of $1 \mathrm{X}$ binding buffer were added to each tube, and the cells were analyzed immediately using a FACSCalibur flow cytometer (BD Biosciences). Data analysis was performed using FlowJo software (BD Biosciences), and FACS measurements were performed for at least 3 independent experiments.
Cell cycle analysis. Cell cycle distribution was determined by staining DNA with PI (Invitrogen; Thermo Fisher Scientific). At $48 \mathrm{~h}$ following transfection, the cells were fixed with cooled $100 \%$ ethanol and stained with $50 \mu \mathrm{g} / \mathrm{ml}$ PI and $1 \mathrm{mg} / \mathrm{ml}$ RNase A for $30 \mathrm{~min}$ at room temperature. Analytical cytometry was performed on a FACSCalibur flow cytometer (BD Biosciences), and cell cycle analysis was performed using FlowJo software (BD Biosciences). FACS measurements were performed for at least 3 independent experiments.

Cell Counting kit-8 (CCK-8) assay. Cell proliferation was determined using the CCK-8 kit (Dojindo Molecular Technologies). Briefly, $3 \times 10^{3}$ cells (A2780) and $2 \times 10^{3}$ cells (SKOV3) were seeded per well in 96-well plates and allowed to adhere overnight prior to transfection. At 0, 24, 48 and $72 \mathrm{~h}$ following transfection, $10 \mu \mathrm{l} \mathrm{CCK}-8$ solution were added to each well for incubation at $5 \% \mathrm{CO}_{2}$ and $37^{\circ} \mathrm{C}$ for an additional $4 \mathrm{~h}$. Finally, the optical density was determined at a wavelength of $450 \mathrm{~nm}$ using a microplate reader (E-MAX, Molecular Devices).

In vitro Transwell invasion and migration assays. The invasion assay was performed using Matrigel (BD Biosciences). Briefly, chilled Matrigel was mixed to homogeneity using a cooled pipette, diluted in serum-free media to a final concentration of $1 \mathrm{mg} / \mathrm{ml}$, and then used to coat a transwell (8-mm pore size polycarbonate membrane) (Corning, Inc.). At $48 \mathrm{~h}$ following transfection, the cells were resuspended in serum-free medium and loaded into each upper well. Medium containing $10 \%$ FBS was added to the lower chamber and served as a chemoattractant. Following overnight incubation, cells were fixed with $4 \%$ formaldehyde for $2 \mathrm{~min}$, permeabilized with $100 \%$ methanol for $2 \mathrm{~min}$ at room temperature, and then stained with $0.1 \%$ crystal violet (Sigma-Aldrich; Merck KGaA) at room temperature for $10 \mathrm{~min}$. Cells on the upper surface of the Transwell were removed using cotton swabs. A Transwell without Matrigel was used for the migration assay, which was performed in the same manner as the invasion assay. Subsequently, each chamber with the invaded or migrated cells was soaked in $0.5 \mathrm{ml} 10 \%$ acetic acid for 1 min to wash out the crystal violet. Subsequently, $10 \%$ acetic acid was added at $200 \mu \mathrm{l} /$ well to 96 -well plates, and the absorbance was measured at a wavelength of $562 \mathrm{~nm}$ using a microplate reader (Molecular Devices).

In vitro wound healing assay. Cell motility was measured using the in vitro wound healing assay using a Culture-Insert (Ibidi) according to the manufacturer's instructions. Briefly, at $48 \mathrm{~h}$ following transection, the cells were resuspended and seeded on each side of a culture insert. The inserts were then placed into wells of a plate and incubated at $37^{\circ} \mathrm{C}$ and $5 \% \mathrm{CO}_{2}$ to allow the cells to grow to confluence. Subsequently, the inserts were removed with sterile tweezers to create a cell-free area ('defined wound') of $\sim 500 \mu \mathrm{m}$. The migration rate into this 'wound area' was measured after the indicated times (A2780: 0, 24 and $48 \mathrm{~h}$; SKOV3: 0, 3 and $6 \mathrm{~h}$ ).

Statistical analysis. Data are presented as the means \pm SEM derived from 3 independent experiments. Differences among multiple groups were analyzed using one-way ANOVA 
followed by Student-Newman-Keuls test. Differences between negative control and $\mathrm{Bcl} 2110$ siRNA-treated groups were analyzed using the Student's t-test. A value of $\mathrm{P}<0.05$ was considered to indicate a statistically significant difference.

\section{Results}

Bcl2l10 expression in various human cancer tissues. In a previous study by the authors, it was determined that $\mathrm{Bcl} 2110$ was not expressed in mouse somatic cells, such as ovarian cumulus and granulosa cells, but was detected in oocytes (12). In the present study, to determine the expression of $\mathrm{Bcl} 2110$ in human cancer tissues, a tissue microarray analysis was performed. The results revealed that $\mathrm{Bcl} 2110$ was expressed in various human cancer tissues, including papillary thyroid carcinoma, lymph node metastatic papillary carcinoma, colon adenocarcinoma, kidney renal cell carcinoma, stomach adenocarcinoma, hepatocellular carcinoma, ovarian clear cell carcinoma and rectum adenocarcinoma tissues. $\mathrm{Bcl} 2110$ was particularly highly expressed in thyroid and lymph node cancer tissues (Fig. 1). These data support the possibility that $\mathrm{Bcl} 2110$ is a cancer-related gene.

Expression and localization of Bcl2llo in human ovarian cancer cell lines. Prior to the analysis of the role of $\mathrm{Bcl} 2110$ in human ovarian cancer cells, the protein levels of $\mathrm{Bcl} 2110$ were examined in various human ovarian cancer cell lines (TOV-21G, CAOV-3, SKOV3, COV-318, A2780 and OVCAR-3) and a normal primary ovarian epithelial cell line (HOSE). The results indicated that $\mathrm{Bcl} 2110$ protein was expressed in all 6 ovarian cancer cell lines, and the levels were significantly lower in the SKOV3 and COV-318 cells, and also tended to decrease in the TOV-21G and OVCAR-3 cells compared to the levels in the normal ovarian cell line, HOSE cells (Fig. 2A). The level of Bcl2110 in the A2780 cells was significantly higher than that in HOSE cells. Since the A2780 cells expressed the highest level of $\mathrm{Bcl} 2110$, whereas the SKOV3 expressed the lowest level of Bcl2110 among the 6 ovarian cancer cell lines, the A2780 and SKOV3 cells were selected for use in further experiments to determine the role of $\mathrm{Bcl} 2110$ in ovarian cancer cells. Additionally, the expression of Aurka was observed in normal ovarian cell and ovarian cancer cells. In the HOSE cells, Aurka protein was not expressed as Aurka is a well-known oncogene (32-34) (Fig. 2A). Of note, the expression pattern of Aurka protein in the 6 ovarian cancer cell lines was opposite to that of $\mathrm{Bcl} 2110$ protein. In other words, the TOV-21G, CAOV-3 and A2780 cells expressed high levels of Bcl2110 and expressed low levels of Aurka, whereas the SKOV3 and COV-318 cells expressed low levels of Bcl2110 and high levels of Aurka (Fig. 2A).

To investigate the intracellular localization of $\mathrm{Bcl} 2110$ in ovarian cancer cells, immunofluorescence staining of the HOSE, A2780 and SKOV3 cells was performed. The results revealed $\mathrm{Bcl} 2110$ that was mainly expressed in the nuclei of all 3 cell lines (Fig. 2B-D).

Bcl2l10 regulates the expression and catalytic activity of Aurka in ovarian cancer cells. Based on a previous finding that $\mathrm{Bcl} 2110$ regulates the expression and activities of Aurka in mouse oocytes as a master regulator of Aurka (14), this study investigated whether $\mathrm{Bcl} 2110$ also affects Aurka expression in ovarian cancer cells by western blot analysis. The protein levels of Bcl2110 and Aurka were decreased following the knockdown of Bcl 2110 by siRNA in the A2780 and SKOV3 cells (Fig. 3A and B). In addition, to determine whether Aurka activity was affected by Bcl2110, cytoplasmic and nuclear protein fractions were harvested from negative control- and Bcl2l10 siRNA-transfected cells, and the kinase activity of Aurka was measured by the colorimetric method. The results revealed that both the cytoplasmic and nuclear Aurka activity were significantly reduced in the $\mathrm{Bcl} 2110$ siRNA-transfected A2780 and SKOV3 cells (Fig. 3C). These results are consistent with our previous findings (14) using mouse oocytes and indicated that $\mathrm{Bcl} 2110$ regulates the expression and activities of Aurka in ovarian cancer cells.

Bcl2l10 knockdown affects Aurka protein stability in ovarian cancer cells. As a decrease in Aurka expression was observed after $\mathrm{Bcl} 2110$ knockdown, we then determined whether Bcl2110 regulates Aurka stability in ovarian cancer cells. Following transfection with negative control or Bcl2110 siRNA into the A2780 and SKOV3 cells, the cells were treated with cycloheximide to inhibit de novo protein synthesis. Protein lysates were harvested at 30-min intervals following cycloheximide treatment, and western blot analysis was performed to investigate Aurka stability. The expression of Aurka declined rapidly in both cell lines following transfection with Bcl2110 siRNA (Fig. 4). These results indicate that $\mathrm{Bcl} 2110$ contributes to Aurka protein stability, which explains the decrease in Aurka protein levels by Bcl2110 knockdown.

Bcl2l10 knockdown does not affect the apoptotic death of ovarian cancer cells. As $\mathrm{Bcl} 2110$ is a member of the apoptotic gene family, it was hypothesized that $\mathrm{Bcl} 2110$ may affect the apoptosis of ovarian cancer cells. To examine this hypothesis, the A2780 and SKOV3 cells were transfected with negative control or Bcl2110 siRNA. The percentage of apoptotic cells was then evaluated using flow cytometric analysis with Annexin V/PI double staining. Annexin $\mathrm{V}^{-} / \mathrm{PI}^{-}$staining indicates viable cells, which are not permeable to PI due to their intact cell membranes. $\mathrm{AV}^{+} / \mathrm{PI}^{-}$staining indicates early apoptotic cells; such staining occurs due to the loss of plasma membrane asymmetry and the strong affinity of AV-FITC with phosphatidylserine. $\mathrm{AV}^{+} / \mathrm{PI}^{+}$staining is indicative of late apoptotic cells. As shown in Fig. 5, no significant difference was observed in either early or late apoptosis between the negative control- and Bcl2110 siRNA-transfected A2780 cells (Fig. 5A). In the SKOV3 cells, the knockdown of $\mathrm{Bcl} 2110$ seemed to decrease the percentage of cells in early apoptosis, although this was not statistically significant. The percentage of cells in late apoptosis was not affected by treatment with $\mathrm{Bcl} 2110$ siRNA (Fig. 5B). Almost all of the A2780 and SKOV3 cells transfected with Bcl2110 siRNA were viable cells, as evidenced by $\mathrm{AV}^{-} / \mathrm{PI}^{-}$staining (93.9 and $94.5 \%$, respectively). The results suggest that Bcl2110 does not affect the apoptosis of ovarian cancer cells.

Bcl2l10 knockdown promotes the proliferation of ovarian cancer cells. To determine the effects of $\mathrm{Bcl} 2110$ on the 

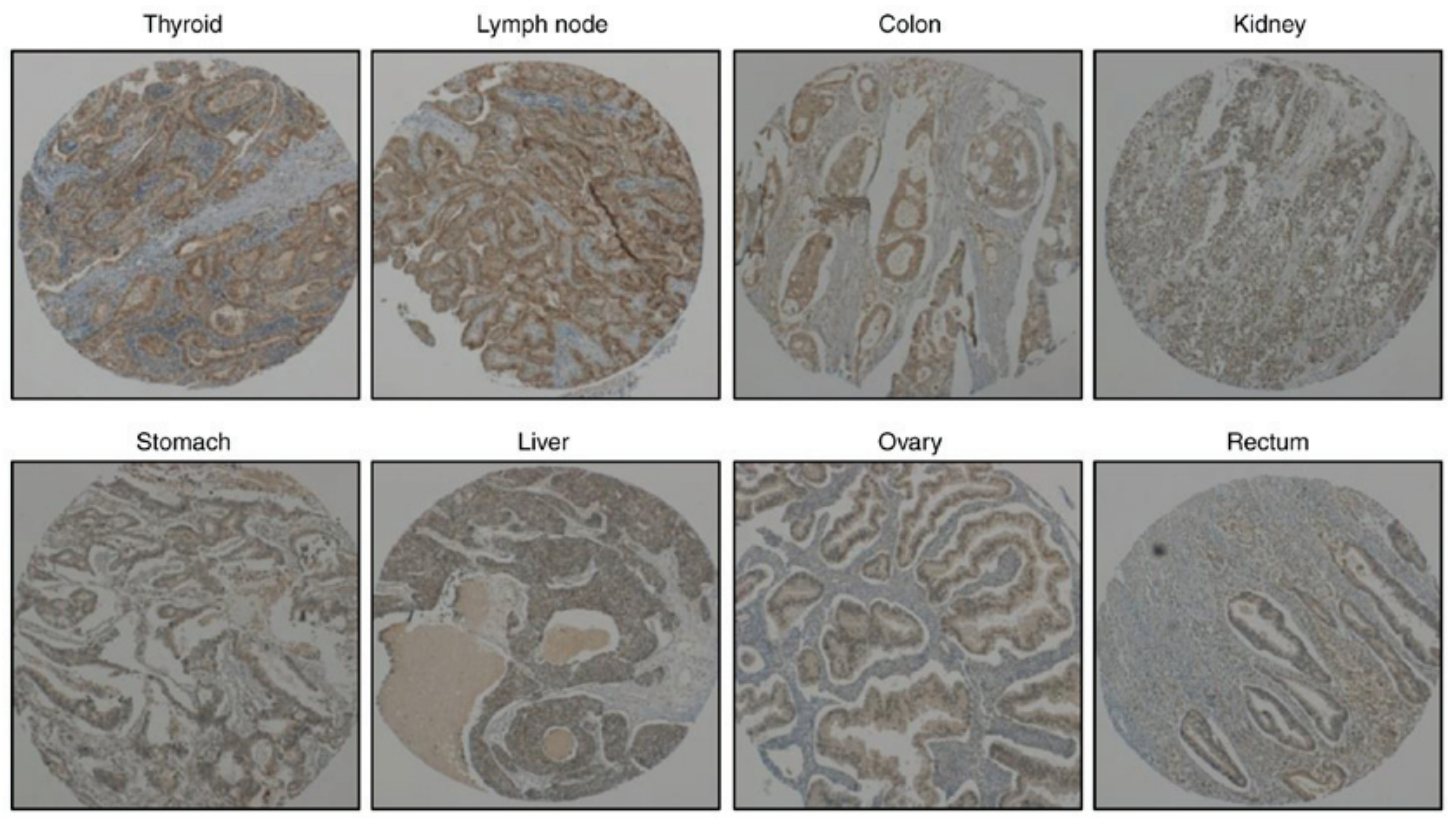

Figure 1. Immunohistochemical staining of Bcl2110 in various human cancer tissues. To detect Bcl2110 expression in cancer tissues, immunohistochemical staining with an anti-Bcl2110 antibody was performed.

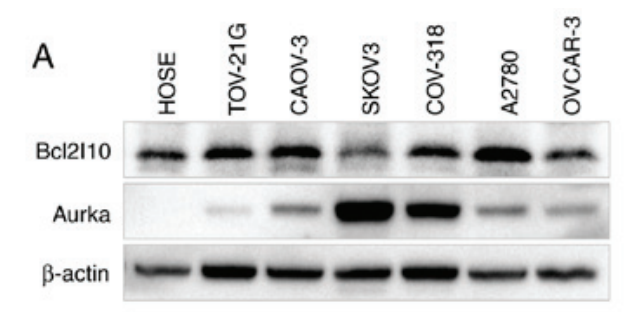

B
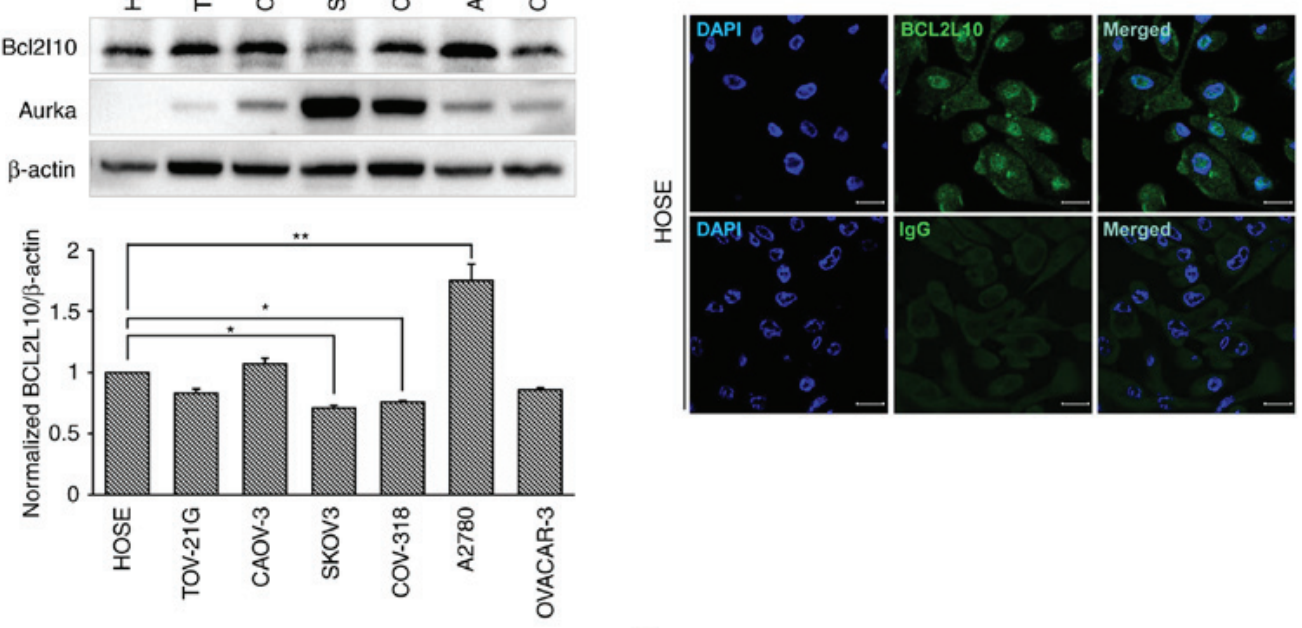

C

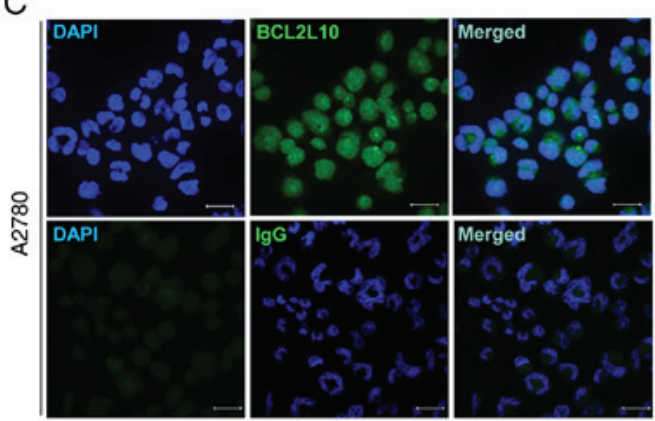

$\mathrm{D}$

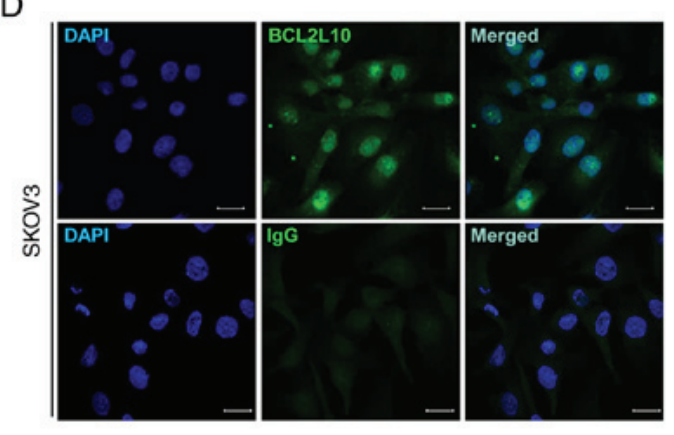

Figure 2. Expression and localization of Bcl2110 in ovarian cancer cell lines. (A) Different protein levels of Bcl2110 and Aurka in 6 human ovarian cancer cell lines and a normal primary ovarian epithelial cell (HOSE) were confirmed by western blot analysis. $\beta$-actin was used as an internal control gene. Signals of Bcl2110 were measured and normalized to corresponding $\beta$-actin signals. Relative expression levels of Bcl2110 were calculated by comparing all the normalized signals to that of HOSE group (to which a value of 1 was assigned). Asterisks indicate statistical significance at ${ }^{*} \mathrm{P}<0.05$ and ${ }^{* *} \mathrm{P}<0.01$. P-values were obtained by one-way ANOVA and Student-Newman-Keuls test. Experiments were repeated at least 3 times, and data are expressed as the means \pm SEM. It was observed that the A2780 cells expressed the highest level of Bcl2110, whereas the SKOV3 cells expressed the lowest level of Bcl2110. (B-D) Localization of Bcl2110 in (B) HOSE, (C) A2780 and (D) SKOV3 cells was determined using immunofluorescence staining. Cells were stained with either control rabbit IgG (IgG) or anti-Bcl2110 antibodies (Bcl2110), followed by incubation with FITC-conjugated goat anti-rabbit IgG antibodies. DNA was labeled with DAPI (DAPI) was mainly detected in nuclei of all 3 cell lines (magnification, x600; scale bar, $20 \mu \mathrm{m}$ ). Aurka, Aurora kinase A. 


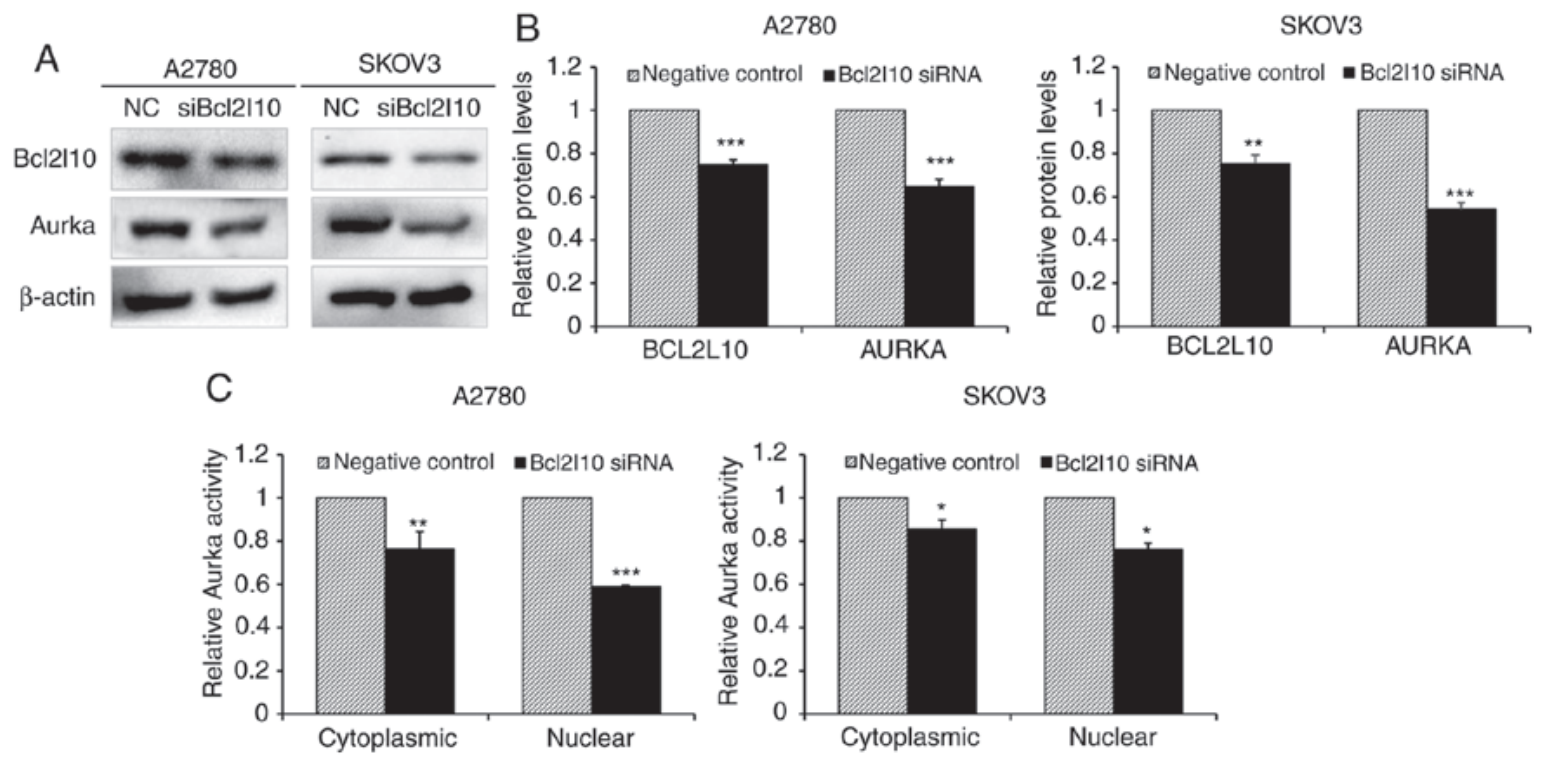

Figure 3. Bc12110 knockdown alters the protein expression of Aurka. (A) A2780 and SKOV3 cells were transfected with negative control or Bcl2110 siRNA and harvested $48 \mathrm{~h}$ following transfection. The protein levels of Bcl2110 and Aurka were measured by western blot analysis. $\beta$-actin was used as an internal control gene. (B) Signals of Bcl2110 and Aurka were measured and normalized to corresponding-actin signals. Relative expression levels of Bcl2110 and Aurka were calculated by comparing all the normalized signals to that of the negative control group (to which a value of 1 was assigned). Experiments were repeated at least 3 times, and data are expressed as the means \pm SEM. (C) Cytoplasmic and nuclear protein fractions were harvested following transfection of the A2780 and SKOV 3 cells, and the kinase activity of Aurka was measured by ELISA at OD $450 \mathrm{~nm}$. Asterisks indicate statistical significance at ${ }^{*} \mathrm{P}<0.05,{ }^{* *} \mathrm{P}<0.01$ and ${ }^{* * * *} \mathrm{P}<0.001$. Experiments were repeated at least 3 times, and data are expressed as the means \pm SEM. Aurka, Aurora kinase A; NC, negative control.
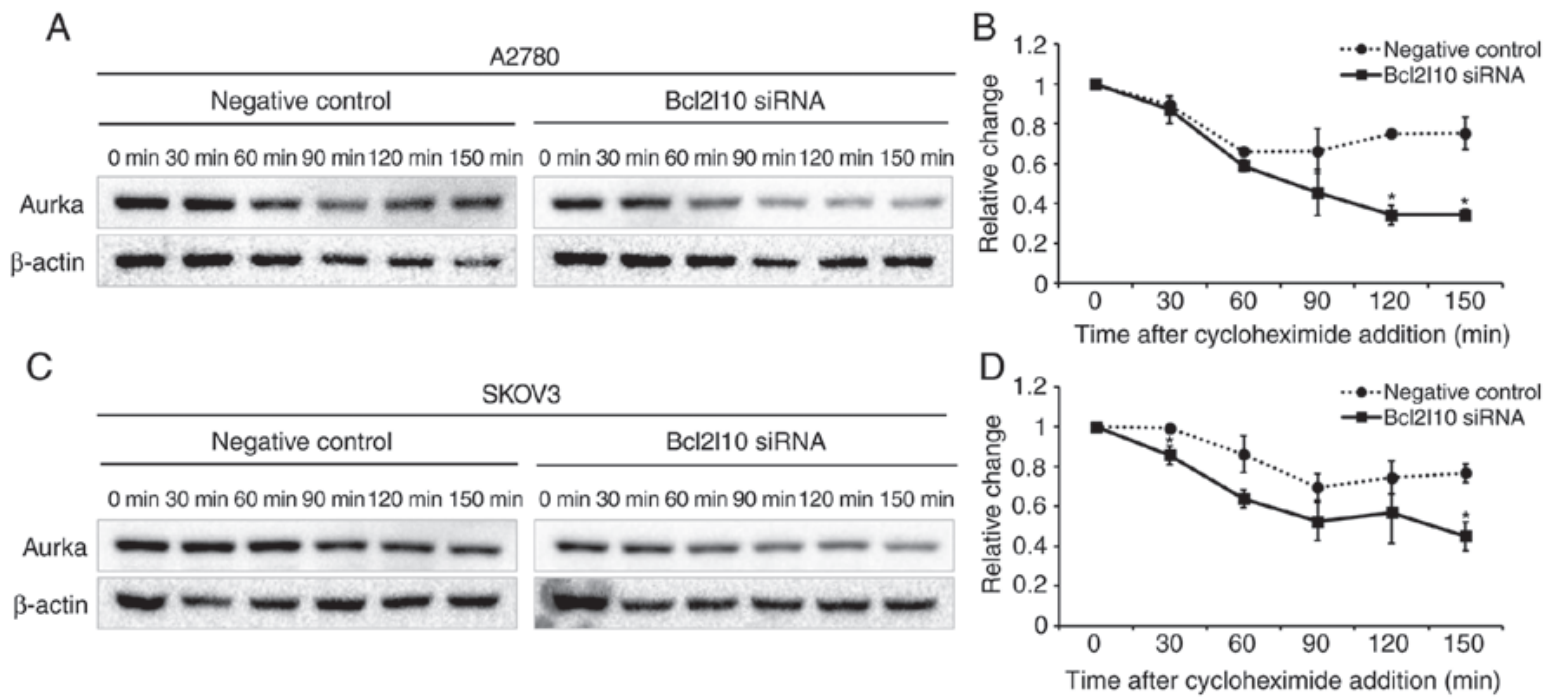

Figure 4. Bcl2110 regulates the protein stability of Aurka in A2780 and SKOV3 cells. (A and C) A2780 and SKOV3 cells were treated with $50 \mu \mathrm{g} / \mathrm{ml}$ cycloheximide $48 \mathrm{~h}$ following transfection. Cells were then harvested at the indicated time points, and the levels of Aurka protein were examined by western blot analysis. $\beta$-actin was used as an internal control gene. (B and D) Densitometric quantification of the western blot results. Asterisks indicate statistical significance at ${ }^{*} \mathrm{P}<0.05$. Experiments were repeated at least 3 times, and data are expressed as the means \pm SEM. Aurka, Aurora kinase A.

viability of ovarian cancer cells, aCCK-8 assay was performed for $72 \mathrm{~h}$ following siRNA transfection. As shown in Fig. 6, the proliferation of the A2780 and SKOV3 cells transfected with Bcl2110 siRNA increased in a time-dependent manner relative to the rate of negative control-siRNA-transfected cells. At $72 \mathrm{~h}$ after Bcl 2110 siRNA transfection, Bcl2110 knockdown led to an increase in the proliferation rate of 21 and $24 \%$ in the A2780 and SKOV3 cells, respectively (Fig. 6). These results suggest that endogenous $\mathrm{Bcl} 2110$ suppresses the proliferation of ovarian cancer cells.
Bcl2l10 knockdown induces cell cycle arrest at the G0/G1 phase by regulating G0/G1-related regulatory genes in ovarian cancer cells. To examine whether the effects of $\mathrm{Bcl} 2110$ on cell proliferation are mediated via cell cycle regulation, cell cycle changes were assessed using flow cytometry following Bcl2110 siRNA transfection. It was expected that Bcl2110 knockdown would decrease the cell population in the G0/G1 phase and would increase it in the G2/M phase due to the above-mentioned finding that cell proliferation was enhanced by $\mathrm{Bcl} 2110$ suppression. However, following Bcl2110 

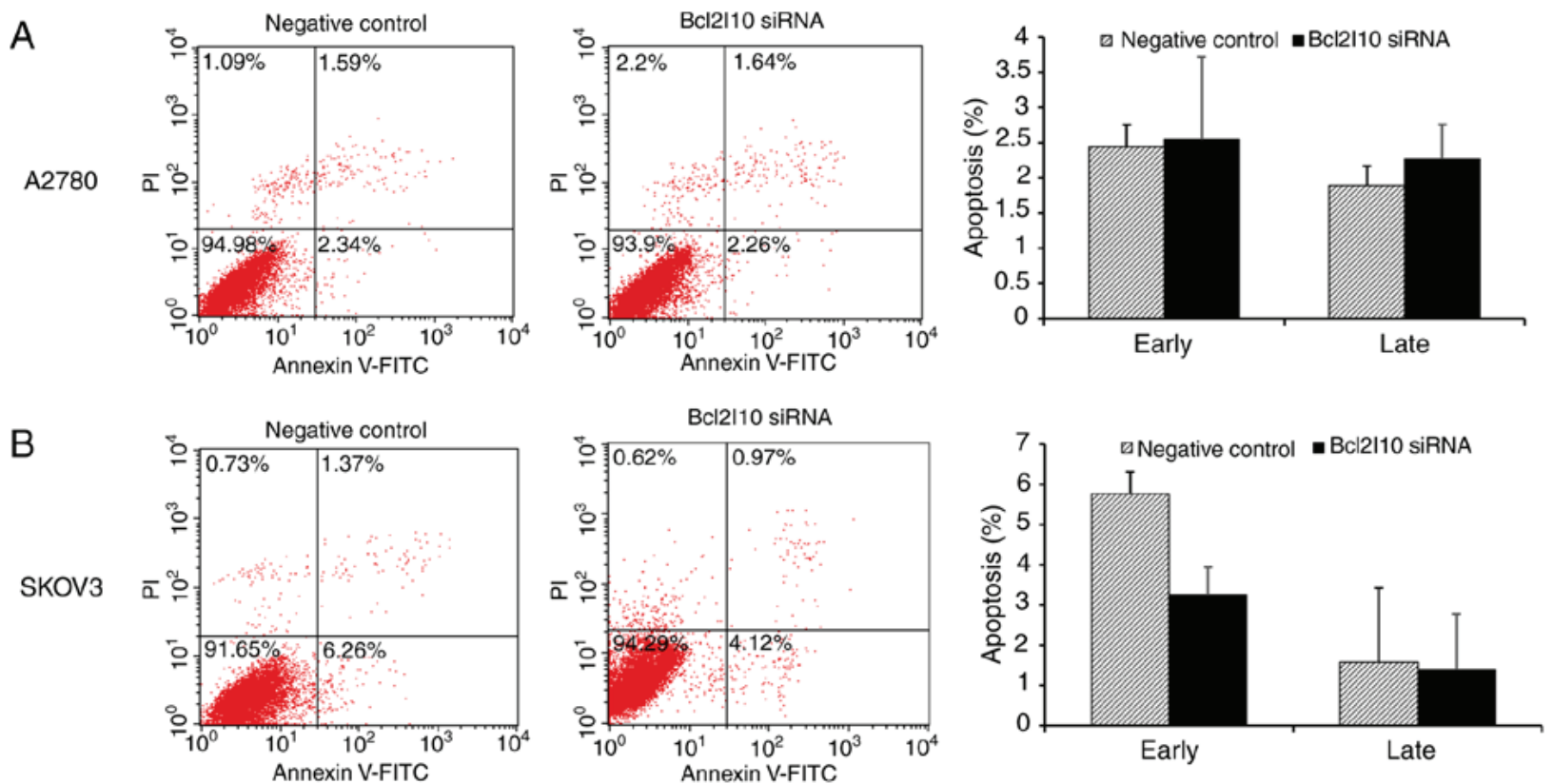

Figure 5. Bc12110 knockdown does not affect the apoptosis of A2780 and SKOV3 cells. At $48 \mathrm{~h}$ post-transfection (A) A2780 and (B) SKOV3 cell apoptosis was determined by flow cytometric analysis of Annexin V and PI staining. The right panel illustrates the rate of early and late apoptotic cells. Experiments were repeated at least 3 times, and data are expressed as the means \pm SEM.

A

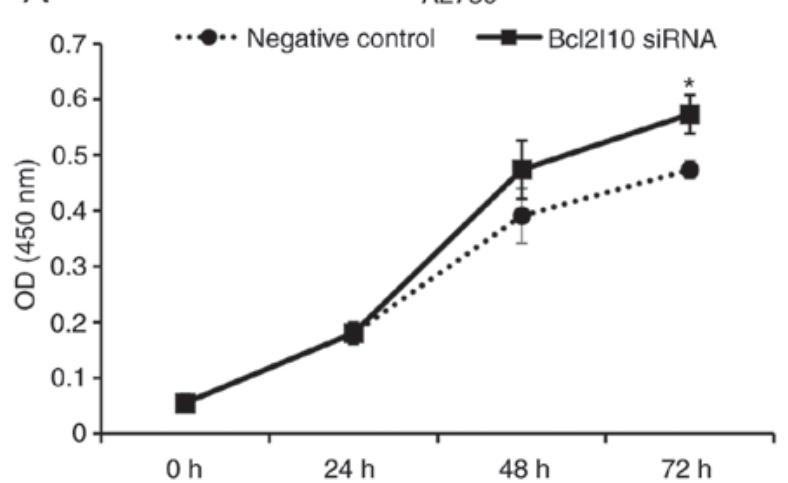

B

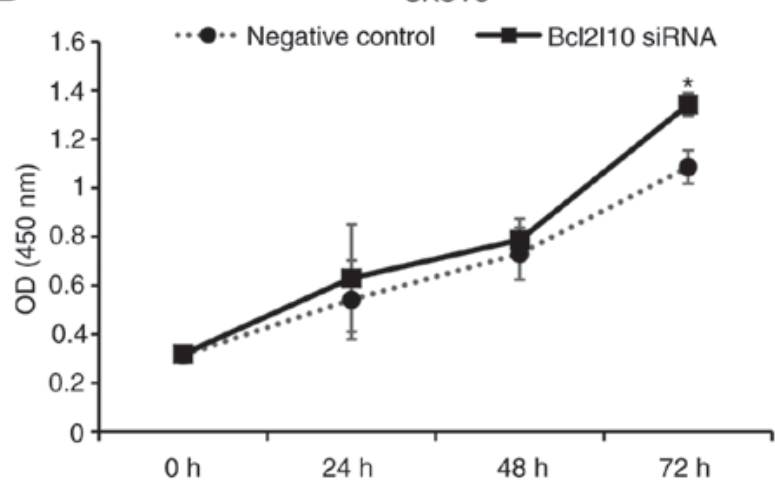

Figure 6. Bc12110 knockdown stimulates the proliferation of A2780 and SKOV3 cells. (A and B) Proliferation of A2780 and SKOV3 cells transfected with negative control or Bcl2110 siRNA was detected for $72 \mathrm{~h}$ by CCK-8 assay at OD $450 \mathrm{~nm}$. Asterisks indicate statistical significance at "P<0.05. Experiments were repeated at least 3 times, and data are expressed as the means \pm SEM.

knockdown in the A2780 and SKOV3 cells, the percentage of cells in the G0/G1 phase was increased in the A2780 cells $(60.5 \%$ in the control group vs. $67.2 \%$ in the Bcl2110 siRNA-transfected group) and SKOV3 cells (71.5\% in the control group vs. $76.9 \%$ in the Bcl2110 siRNA-transfected group), whereas the percentages of cells in the $\mathrm{S}$ and $\mathrm{G} 2 / \mathrm{M}$ phases were slightly decreased (Fig. 7A and B). These results indicated that Bcl2110 knockdown induced cell cycle arrest at the G0/G1 phase in ovarian cancer cells.

To investigate the mechanisms underlying the induction of cell cycle arrest at the G0/G1 phase, the levels of cyclins and CDKs that regulate the G0/G1 phase were examined by western blot analysis. In both the A2780 and SKOV3 cells, the levels of CDK4 and cyclin D1 were significantly decreased by Bcl2110 knockdown relative to the levels in the control group (Fig. 7C and D). Subsequently, the authors determined whether CDK inhibitors (CDKIs), such as p27, p21 and p16, which are known as inhibitors of CDK4, are affected by Bcl2110 knockdown (35). In the Bcl2110 siRNA-transfected group of A2780 cells, the levels of p27 and p21 were significantly decreased, whereas the level of p16 was markedly increased (Fig. 7C). By contrast, in the SKOV3 cells, Bcl2110 knockdown markedly increased the levels of p27 and p21, whereas the expression of p16 was not markedly unaffected (Fig. 7D). Taken together, these results suggest that Bcl2110 mediates cell cycle progression in the G0/G1 phase via the regulation of G0/G1-related cyclins, CDKs and CDKIs in ovarian cancer cells.

Bcl2l10 knockdown promotes the migration and invasion of ovarian cancer cells. The roles of Bcl2110 in cell migration and invasion were then assessed using Transwell assays. The results revealed that the numbers of migrated and invaded cells were increased by Bcl2110 suppression (Fig. 8A and C). 
A

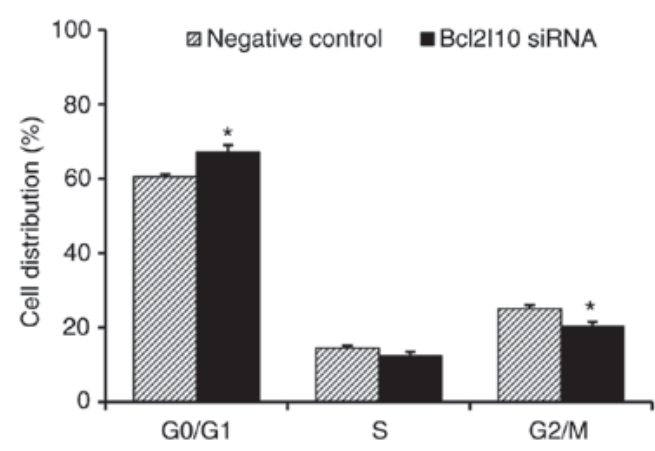

C

A2780
A2780
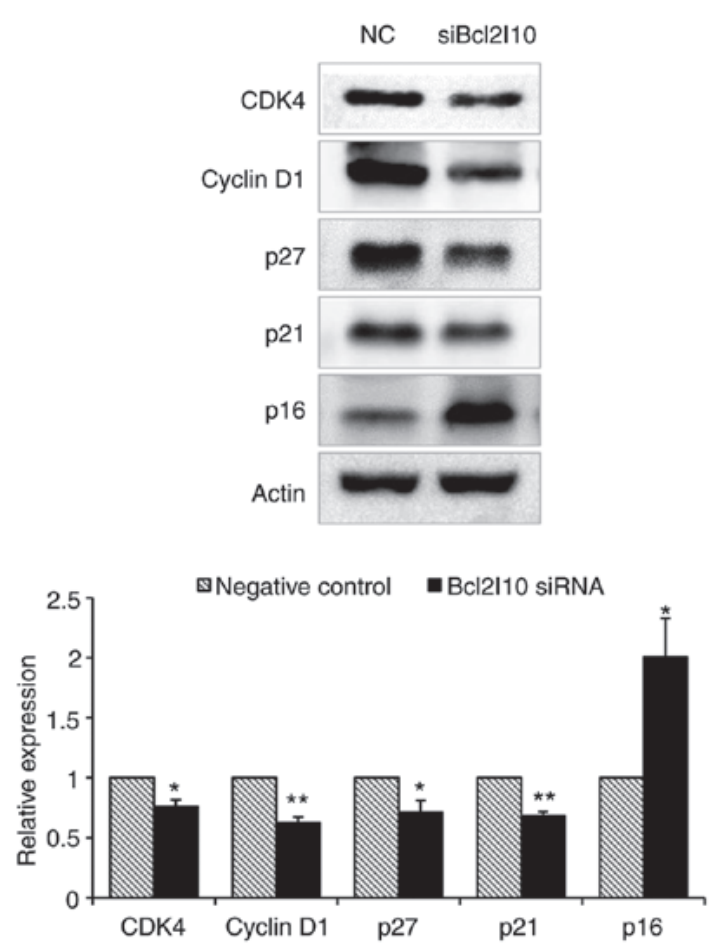

B

SKOVз

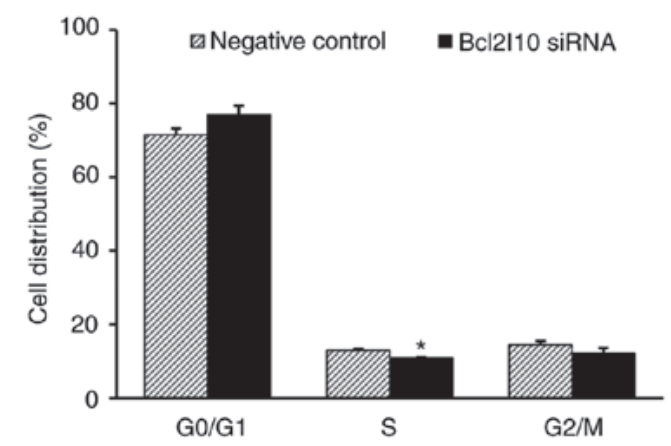

D

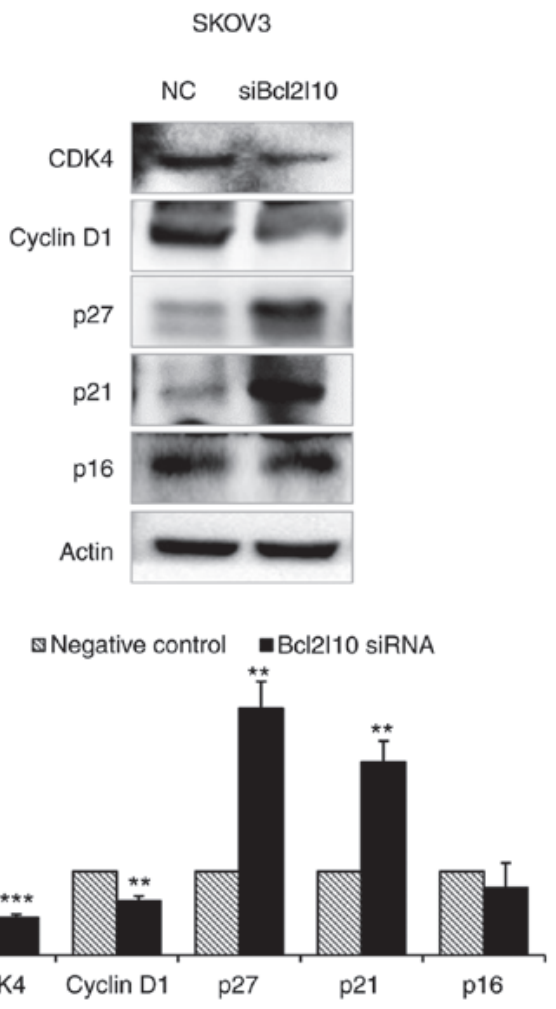

Figure 7. Bcl2110 knockdown induces cell cycle arrest at the G0/G1 phase in A2780 and SKOV3 cells. (A and B) Cell cycle analysis was performed $48 \mathrm{~h}$ following transfection by a FACSCalibur flow cytometer, and at least 10,000 cells were analyzed per sample. Asterisks indicate statistical significance at ${ }^{*} \mathrm{P}<0.05$. Experiments were repeated at least 3 times and one replicate was used for each experiment. Data are expressed as the means \pm SEM. (C and D) G0/G1-related proteins were examined following transfection by western blot analysis. $\beta$-actin was used as an internal control gene. Signals of each gene were measured and normalized to corresponding $\beta$-actin signals. Relative expression levels of each gene were calculated by comparing all the normalized signals to that of the negative control group (to which a value of 1 was assigned). Asterisks indicate statistical significance at ${ }^{*} \mathrm{P}<0.05,{ }^{* *} \mathrm{P}<0.01$ and ${ }^{* * *} \mathrm{P}<0.001$. Experiments were repeated at least 3 times, and data are expressed as the means \pm SEM.

The rates of migration and invasion were quantified using the dissolved crystal violet from cells passing through the Transwell chamber. In the A2780 cells, the migratory and invasive abilities were increased by 24.4 and $22.6 \%$, respectively, in the $\mathrm{Bcl} 2110$ siRNA-transfected group relative to the control group (Fig. 8B). Similarly, upon Bcl2110 siRNA treatment, 32.2 and $45.9 \%$ of SKOV3 cells exhibited increased migratory and invasive abilities, respectively, relative to the abilities of the control cells (Fig. 8D). The migratory abilities were further confirmed by wound healing assay. Bcl2110 knockdown enhanced the motility of both the A2780 and SKOV3 cells (Fig. 8E and G). After 48 h, the A2780 cells filled 43.1 and $64.3 \%$ of the wound area in the control and $\mathrm{Bcl} 2110$ siRNA-transfected group, respectively (Fig. 8F). After 6 h, the
SKOV3 cells filled 38.4 and $50.4 \%$ of the wound area in the control and Bcl2110 siRNA-transfected group, respectively (Fig. $8 \mathrm{H}$ ). These data suggest that $\mathrm{Bcl} 2110$ contributes to the regulation of the invasion and migration of ovarian cancer cells in vitro.

\section{Discussion}

The present study investigated the functions of Bcl2110 in ovarian cancer cells. Previously, it was found that $\mathrm{Bcl} 2110$ is a master regulator of Aurka in mouse oocytes. Aurka is reportedly overexpressed in a number of malignancies, including breast, liver, pancreatic and ovarian cancers, inducing tumor progression $(32,36)$. As Aurka has been considered as an 
A

A2780

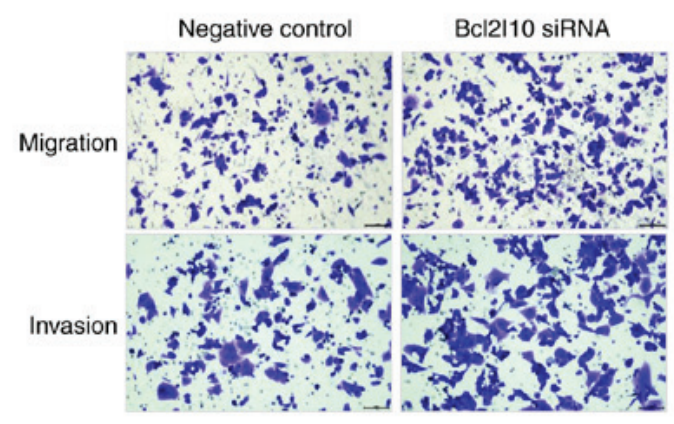

B

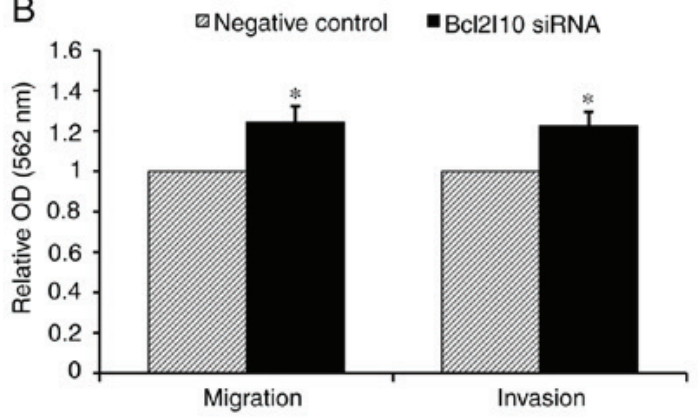

E

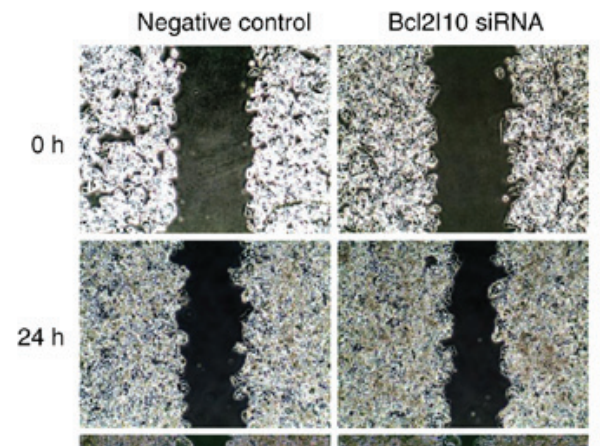

$48 h$

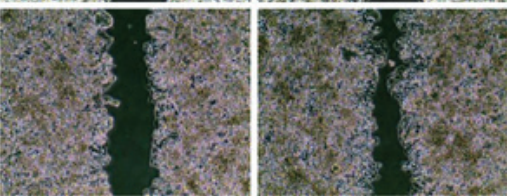

$\mathrm{F}$

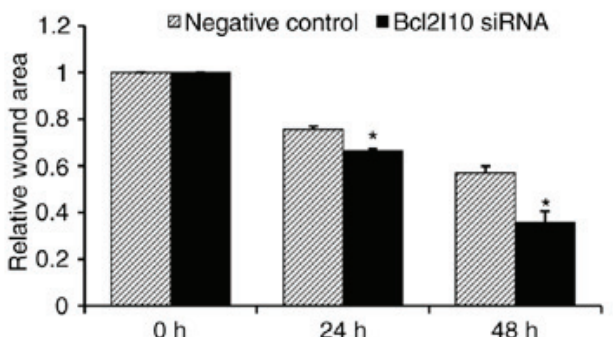

C
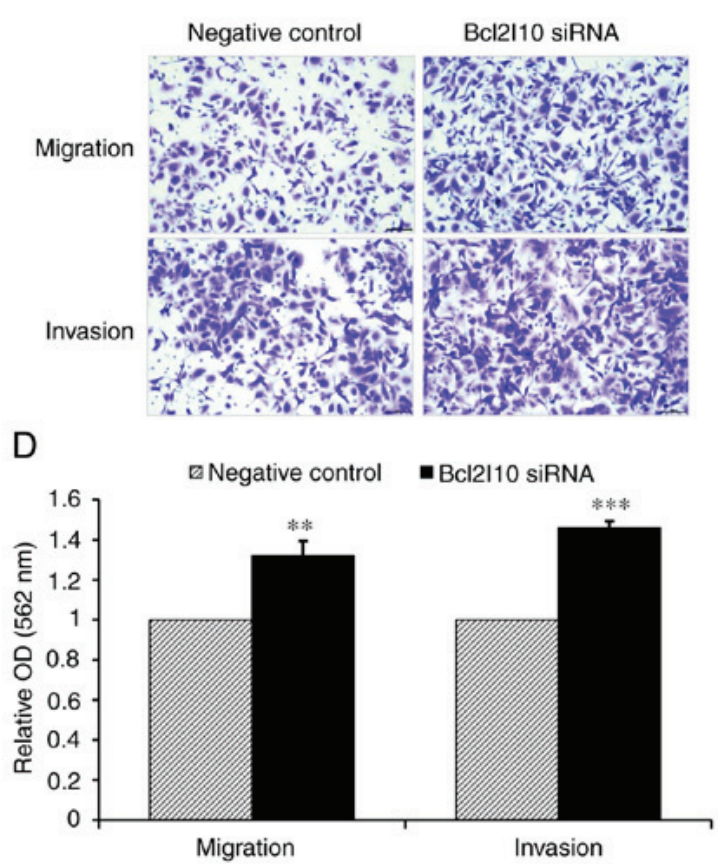

G

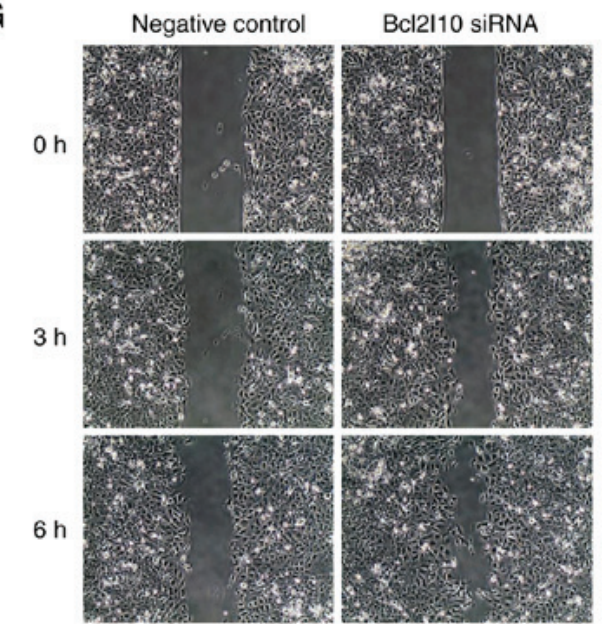

$\mathrm{H}$

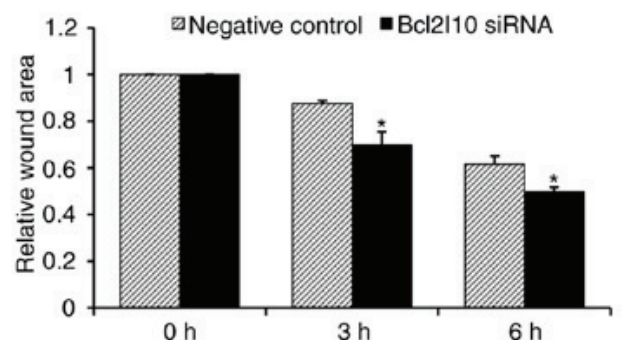

Figure 8. Bcl2110 knockdown enhances the migration and invasion of A2780 and SKOV3 cells. (A and C) A2780 and SKOV3 cells transfected with negative control or Bcl2110 siRNA were subjected to Transwell assay at $48 \mathrm{~h}$ following transfection. The migrated and invaded cells were photographed under a light microscope and quantified by measuring dissolved crystal violet at OD $595 \mathrm{~nm}$. (B and D) The bar graph exhibits the relative percentages of migrated and invaded cells. Asterisks indicate statistical significance at ${ }^{*} \mathrm{P}<0.05,{ }^{* * *} \mathrm{P}<0.01$ and ${ }^{* * * *} \mathrm{P}<0.001$. Experiments were repeated at least 3 times, and data are expressed as the means \pm SEM. (E and G) A wound healing assay was performed with A2780 and SKOV3 cells $48 \mathrm{~h}$ following transfection. An artificial scratch was made vertically in each group of cells. The wound recovery was then monitored and photographed under a light microscope. (F and $\mathrm{H}$ ) Cell motility was assessed by calculating the relative wound area at the indicated time points in A2780 and SKOV3 cells. The bar graph shows the percentage mean wound area. Asterisks indicate statistical significance at ${ }^{*} \mathrm{P}<0.05$. Experiments were repeated at least 3 times, and data are expressed as the means \pm SEM.

important target for cancer therapy (37), it was hypothesized that if $\mathrm{Bcl} 2110$ regulates tumor progression depending on Aurka, the targeting of Bcl2110 could be used in combination with Aurka inhibitor to generate synergistic anticancer effects.
Of note, it was found that cells expressing high levels of Bcl2110 expressed low levels of Aurka, whereas cells expressing low levels of Bcl2110 expressed high levels of Aurka. In addition, there were also differences in baseline 
Aurka activity between the A2780 and SKOV3 cells (data not shown). The Aurka activities in the nuclei of SKOV3 cells were higher than those of the A2780 cells, corresponding with the results that the expression of Aurka was higher in the SKOV3 than in the A2780 cells. These results provide evidence that $\mathrm{Bcl} 2110$ regulates Aurka expression in ovarian cancer cells. As was expected, the knockdown of Bcl2110 decreased the protein expression and activity of Aurka in A2780 and SKOV3 cells. It has been widely reported that the silencing of Aurka expression by siRNA or treatment with the Aurka inhibitor, MLN8237, blocks cancer progression by inducing apoptosis, cell cycle arrest at the $\mathrm{G} 2 / \mathrm{M}$ phase, autophagy, aneuploidy and mitotic spindle failure in a number of types of cancer (38-41). However, this study obtained contradictory results from Bcl2110-silenced cells, which exhibited phenotypic alterations different from those of Aurka-silenced cells. The knockdown of Bcl2110 stimulated cell proliferation and mobility, whereas it induced cell cycle arrest at the G0/G1 phase without affecting the apoptosis of A2780 and SKOV3 cells.

Although there are contradictory data, relatively lower expression levels of $\mathrm{Bcl} 2110$ in ovarian cancer cells and increased cell proliferation and motility by Bcl2110 knockdown are sufficient to conclude that $\mathrm{Bcl} 2110$ is a tumor suppressor in ovarian cancer cells. Genomic instability is a hallmark of malignant transformation (42) and the effects of the gain or loss of a single gene are likely to be transmitted throughout the genome with the consequence that the expression of other genes becomes secondarily modulated (43). Therefore, it was hypothesized that the stimulation of cell proliferation by Bcl2110 knockdown was caused by changes in the expression or stability of other Bcl2110-related genes rather than Aurka downregulation. Although Bcl2110 knockdown decreased Aurka expression, the effects of other genes whose expression was altered by Bcl2110 knockdown may be greater than that of decreased Aurka expression.

$\mathrm{Bcl} 2110$ is a member of the Bcl-2 family that regulates the balance between apoptosis and autophagy (2). In the present study, the authors hypothesized that the depletion of $\mathrm{Bcl} 2110$ may alter the apoptotic rate of ovarian cancer cells; however, $\mathrm{Bcl} 2110$ knockdown did not affect the apoptotic rate. The apoptotic regulation of $\mathrm{Bcl} 2110$ is reportedly cell- or tissue-specific. The roles of proteins are determined by their components based on cellular content, protein interactions or external stimuli. However, the mechanisms underlying the divergent cell- or tissue-specific activities of Bcl2110 have not yet been clarified (5-10). Contributing to the conflicting results in a number of tissues, this study demonstrated that Bcl2110 had no effect on the apoptosis of A2780 and SKOV3 cells. Thus, $\operatorname{Bcl} 2110$ may not be a dominant regulator of the apoptosis of ovarian cancer cells.

Cancer occurs due to inappropriate cell proliferation $(44,45)$. In normal cells, the cell cycle is exquisitely controlled by signaling pathways for cell growth and includes processes to correct errors that occur during cell division (46). Cancer cells can overcome these errors through the abnormal expression of cyclins and CDKs, allowing them to undergo unregulated cell growth (47). In the present study, Bcl2110 knockdown induced cell cycle arrest at the G0/G1 phase through the upregulation of
CDK inhibitors (p16, p21 and p27) followed by the suppression of CDK4 and cyclin D1. Cell cycle arrest represents a survival mechanism that provides cancer cells the opportunity to repair their own damaged DNA, and cell cycle retardation can activate the apoptotic cascade, leading to cancer cell death (48). In this study, it was found that the proliferation rate of Bcl2110-silenced cells was significantly increased relative to that of the control cells. These results suggest that $\mathrm{Bcl} 2110$ knockdown facilitates the proliferation of ovarian cancer cells. Taken together, it can be concluded that $\mathrm{Bcl} 2110$ is involved in the cell cycle progression and proliferation of ovarian cancer cells as a tumor suppressor gene.

Metastasis, one of the most important issues in cancer development (49), comprises a series of events. epithelial-mesenchymal transition and mesenchymal-epithelial transition are important events for the metastasis of carcinomas $(50,51)$, whereas cell invasion and migration are important processes in a number of physiological events, such as embryo implantation (52), angiogenesis (53) and inflammation (54). However, cell invasion and migration are also involved in the pathophysiology of a number of diseases, such as neuronal migration disorders, atherosclerosis and cancer $(55,56)$. In this study, it was found that Bcl2110 knockdown increased the number of invading or migrating cells relative to the number among control cells. In the wound healing assay, wounds were rapidly closed by the silencing of $\mathrm{Bcl} 2110$. These results suggest that $\mathrm{Bcl} 2110$ may facilitate the anti-metastatic functions in human ovarian cancer. However, the mechanisms underlying this effect in the present study were not addressed. Further studies are thus required to elucidate the $\mathrm{Bcl} 2110$ signaling network and to determine the mechanisms through which it hinders the invasion and/or migration of ovarian cancer cells.

In conclusion, this study demonstrated that $\mathrm{Bcl} 2110$ regulates expression and activity of Aurka in ovarian cancer cells. Importantly, the present study, to the best of our knowledge, is the first to report that $\mathrm{Bcl} 2110$ plays a role in tumorigenesis and in the proliferation of ovarian cancer cells. To clarify the molecular functions of Bcl2110 in ovarian cancer cells, the authors aim to explore novel Bcl2110-related genes using RNA-Sequencing analysis in future studies. In the future, our results may provide a potential basis for developing ovarian anti-cancer agents targeting $\mathrm{Bcl} 2110$.

\section{Acknowledgements}

Not applicable.

\section{Funding}

This research was supported by the Basic Science Research Program through the National Research Foundation of Korea (NRF) funded by the Ministry of Education (NRF-2016R1A2B4013403).

\section{Availability of data and materials}

All data generated or analyzed during this study are included in this published article or are available from the corresponding author upon reasonable request. 


\section{Authors' contributions}

JHW designed and performed experiments and wrote the manuscript. SYL performed experiments and revised the manuscript. JK provided experimental materials and analyzed the data. KHK was involved in the conception and design of the study. KAL was involved in the conception and design of the study and revised the manuscript. All authors have read and approved the final manuscript.

\section{Ethics approval and consent to participate}

The tissues examined in this study were from a tissue microarray; thus, no ethics approval was required.

\section{Patient consent for publication}

Not applicable.

\section{Competing interests}

The authors declare that they have no competing interests.

\section{References}

1. Adams JM and Cory S: The Bcl-2 protein family: Arbiters of cell survival. Science 281: 1322-1326, 1998.

2. Levine B, Sinha S and Kroemer G: Bcl-2 family members: Dual regulators of apoptosis and autophagy. Autophagy 4: 600-606, 2008.

3. Opferman JT and Korsmeyer SJ: Apoptosis in the development and maintenance of the immune system. Nat Immunol 4: 410-415, 2003.

4. Zong WX, Lindsten T, Ross AJ, MacGregor GR and Thompson CB: $\mathrm{BH} 3$-only proteins that bind pro-survival $\mathrm{Bcl}-2$ family members fail to induce apoptosis in the absence of Bax and Bak. Genes Dev 15: 1481-1486, 2001.

5. Inohara N, Gourley TS, Carrio R, Muñiz M, Merino J, Garcia I, Koseki T, Hu Y, Chen S and Núñez G: Diva, a Bcl-2 homologue that binds directly to Apaf-1 and induces BH3-independent cell death. J Biol Chem 273: 32479-32486, 1998.

6. Kang Y, Lee DC, Han J, Yoon S, Won M, Yeom JH, Seong MJ, Ko JJ, Lee KA, Lee K and Bae J: NM23-H2 involves in negative regulation of Diva and Bcl2L10 in apoptosis signaling. Biochem Biophys Res Commun 359: 76-82, 2007.

7. Mikata R, Yokosuka O, Fukai K, Imazeki F, Arai M, Tada M, Kurihara T, Zhang K, Kanda T and Saisho H: Analysis of genes upregulated by the demethylating agent 5-aza-2'-deoxycytidine in gastric cancer cell lines. Int J Cancer 119: 1616-1622, 2006.

8. Ke N, Godzik A and Reed JC: Bcl-B, a novel Bcl-2 family member that differentially binds and regulates Bax and Bak. J Biol Chem 276: 12481-12484, 2001.

9. Naumann U, Weit S, Wischhusen J and Weller M: Diva/Boo is a negative regulator of cell death in human glioma cells. FEBS Lett 505: 23-26, 2001.

10. Zhang H, Holzgreve W and De Geyter C: Bcl2-L-10, a novel anti-apoptotic member of the Bcl-2 family, blocks apoptosis in the mitochondria death pathway but not in the death receptor pathway. Hum Mol Genet 10: 2329-2339, 2001.

11. Yoon SJ, Kim JW, Choi KH, Lee SH and Lee KA: Identification of oocyte-specific diva-associated proteins using mass spectrometry. Korean J Fertil Steril DE 33: 189-198, 2006.

12. Yoon SJ, Kim EY, Kim YS, Lee HS, Kim KH, Bae J and Lee KA: Role of Bcl2-like 10 (Bcl2110) in regulating mouse oocyte maturation. Biol Reprod 81: 497-506, 2009.

13. Kim EA, Kim KS, Lee HS, Lee S, Kim EY, Seo YM, Bae J and Lee KA: Downstream genes regulated by Bcl2110 RNAi in the mouse oocytes. Dev Reprod 15: 61-69, 2011.

14. Lee SY, Kim EY, Kim KH and Lee KA: Bcl2110, a new Tpx2 binding partner, is a master regulator of Aurora kinase A in mouse oocytes. Cell Cycle 15: 3296-3305, 2016.
15. Joukov V: Aurora kinases and spindle assembly: Variations on a common theme? Cell Cycle 10: 895-903, 2011.

16. Kufer TA, Silljé HH, Körner R, Gruss OJ, Meraldi P and Nigg EA Human TPX2 is required for targeting Aurora-A kinase to the spindle. J Cell Biol 158: 617-623, 2002.

17. Giubettini M, Asteriti IA, Scrofani J, De Luca M, Lindon C, Lavia P and Guarguaglini G: Control of Aurora-A stability through interaction with TPX2. J Cell Sci 124: 113-122, 2011.

18. Giet R, Petretti C and Prigent C: Aurora kinases, aneuploidy and cancer, a coincidence or a real link? Trends Cell Biol 15: 241-250, 2005.

19. Compérat E, Camparo P, Haus R, Chartier-Kastler E, Radenen B, Richard F, Capron F and Paradis V: Aurora-A/STK-15 is a predictive factor for recurrent behaviour in non-invasive bladder carcinoma: A study of 128 cases of non-invasive neoplasms. Virchows Arch 450: 419-424, 2007.

20. Lassmann S, Shen Y, Jütting U, Wiehle $P$, Walch A, Gitsch G, Hasenburg A and Werner M: Predictive value of Aurora-A/STK15 expression for late stage epithelial ovarian cancer patients treated by adjuvant chemotherapy. Clin Cancer Res 13: 4083-4091, 2007.

21. Nishida N, Nagasaka T, Kashiwagi K, Boland CR and Goel A: High copy amplification of the Aurora-A gene is associated with chromosomal instability phenotype in human colorectal cancers. Cancer Biol Ther 6: 525-533, 2007.

22. Jeng YM, Peng SY, Lin CY and Hsu HC: Overexpression and amplification of Aurora-A in hepatocellular carcinoma. Clin Cancer Res 10: 2065-2071, 2004.

23. Anand S, Penrhyn-Lowe S and Venkitaraman AR: AURORA-A amplification overrides the mitotic spindle assembly checkpoint, inducing resistance to Taxol. Cancer Cell 3: 51-62, 2003.

24. Meraldi P, Honda R and Nigg EA: Aurora-A overexpression reveals tetraploidization as a major route to centrosome amplification in p53/- cells. EMBO J 21: 483-492, 2002.

25. Nikonova AS, Astsaturov I, Serebriiskii IG, Dunbrack RL Jr and Golemis EA: Aurora A kinase (AURKA) in normal and pathological cell division. Cell Mol Life Sci 70: 661-687, 2013.

26. Xu JD, Furuya T, Cao XX, Liu XL, Li QQ, Wang WJ, $\mathrm{Xu}$ JW, Xu ZD, Sasaki K and Liu XP: Loss of BCL2L10 protein expression as prognostic predictor for poor clinical outcome in gastric carcinoma. Histopathology 57: 814-824, 2010.

27. Xu JD, Cao XX, Long ZW, Liu XP, Furuya T, Xu JW, Liu XL, De Xu Z, Sasaki K and Li QQ: BCL2L10 protein regulates apoptosis/proliferation through differential pathways in gastric cancer cells. J Pathol 223: 400-409, 2011.

28. Mikata R, Fukai K, Imazeki F, Arai M, Fujiwara K, Yonemitsu Y, Zhang K, Nabeya Y, Ochiai T and Yokosuka O: BCL2L10 is frequently silenced by promoter hypermethylation in gastric cancer. Oncol Rep 23: 1701-1708, 2010.

29. Bai Y, Wang J, Han J, Xie XL, Ji CG, Yin J, Chen L, Wang CK, Jiang XY, Qi W and Jiang HQ: BCL2L10 inhibits growth and metastasis of hepatocellular carcinoma both in vitro and in vivo. Mol Carcinog 56: 1137-1149, 2017.

30. Nougarede A, Popgeorgiev N, Kassem L, Omarjee S, Borel S, Mikaelian I, Lopez J, Gadet R, Marcillat O, Treilleux I, et al: Breast cancer targeting through inhibition of the endoplasmic reticulum-based apoptosis regulator Nrh/BCL2L10. Cancer Res 78: 1404-1417, 2018.

31. Cluzeau T, Robert G, Mounier N, Karsenti JM, Dufies M, Puissant A, Jacquel A, Renneville A, Preudhomme C, Cassuto JP, et al: BCL2L10 is a predictive factor for resistance to azacitidine in MDS and AML patients. Oncotarget 3: 490-501, 2012.

32. Carvajal RD, Tse A and Schwartz GK: Aurora kinases: New targets for cancer therapy. Clin Cancer Res 12: 6869-6875, 2006.

33. Fu J, Bian M, Jiang Q and Zhang C: Roles of Aurora kinases in mitosis and tumorigenesis. Mol Cancer Res 5: 1-10, 2007.

34. Zhou H, Kuang J, Zhong L, Kuo WL, Gray JW, Sahin A, Brinkley BR and Sen S: Tumour amplified kinase STK15/BTAK induces centrosome amplification, aneuploidy and transformation. Nat Genet 20: 189-193, 1998.

35. D'Andrilli G, Kumar C, Scambia G and Giordano A: Cell cycle genes in ovarian cancer: Steps toward earlier diagnosis and novel therapies. Clin Cancer Res 10: 8132-8141, 2004.

36. Gautschi O, Heighway J, Mack PC, Purnell PR, Lara PN Jr and Gandara DR: Aurora kinases as anticancer drug targets. Clin Cancer Res 14: 1639-1648, 2008.

37. Keen $\mathrm{N}$ and Taylor S: Aurora-kinase inhibitors as anticancer agents. Nat Rev Cancer 4: 927-936, 2004. 
38. Zhou N, Singh K, Mir MC, Parker Y, Lindner D, Dreicer R, Ecsedy JA, Zhang Z, Teh BT, Almasan A and Hansel DE: The investigational Aurora kinase A inhibitor MLN8237 induces defects in cell viability and cell-cycle progression in malignant bladder cancer cells in vitro and in vivo. Clin Cancer Res 19: 1717-1728, 2013.

39. Li JP, Yang YX, Liu QL, Pan ST, He ZX, Zhang X, Yang T, Chen XW, Wang D, Qiu JX and Zhou SF: The investigational Aurora kinase A inhibitor alisertib (MLN8237) induces cell cycle G2/M arrest, apoptosis, and autophagy via p38 MAPK and Akt/mTOR signaling pathways in human breast cancer cells. Drug Des Devel Ther 9: 1627-1652, 2015.

40. Görgün G, Calabrese E, Hideshima T, Ecsedy J, Perrone G, Mani M, Ikeda H, Bianchi G, Hu Y, Cirstea D, et al: A nove Aurora-A kinase inhibitor MLN8237 induces cytotoxicity and cell-cycle arrest in multiple myeloma. Blood 115: 5202-5213, 2010.

41. Asteriti IA, Di Cesare E, De Mattia F, Hilsenstein V, Neumann B, Cundari E, Lavia P and Guarguaglini G: The Aurora-A inhibitor MLN8237 affects multiple mitotic processes and induces dose-dependent mitotic abnormalities and aneuploidy. Oncotarget 5: 6229-6242, 2014.

42. Komarova NL: Genomic instability in cancer: Biological and mathematical approaches. Cell Cycle 3: 1081-1085, 2004.

43. Zhang XD: Genome-wide screens for effective siRNAs through assessing the size of siRNA effects. BMC Res Notes 1: 33, 2008.

44. Collins K, Jacks T and Pavletich NP: The cell cycle and cancer. Proc Natl Acad Sci USA 94: 2776-2778, 1997.

45. Jones RG and Thompson CB: Tumor suppressors and cell metabolism: A recipe for cancer growth. Genes Dev 23: 537-548, 2009
46. Malumbres $\mathrm{M}$ and Barbacid $\mathrm{M}$ : Cell cycle, CDKs and cancer: A changing paradigm. Nat Rev Cancer 9: 153-166, 2009.

47. del Rincón SV, Widschwendter M, Sun D, Ekholm-Reed S, Tat J, Teixeira LK, Ellederova Z, Grolieres E, Reed SI and Spruck C: Cks overexpression enhances chemotherapeutic efficacy by overriding DNA damage checkpoints. Oncogene 34: 1961-1967, 2015.

48. Schwartz GK and Shah MA: Targeting the cell cycle: A new approach to cancer therapy. J Clin Oncol 23: 9408-9421, 2005.

49. Spano D, Heck C, De Antonellis P, Christofori G and Zollo M Molecular networks that regulate cancer metastasis. Semin Cancer Biol 22: 234-249, 2012.

50. Kang Y and Massague J: Epithelial-mesenchymal transitions: Twist in development and metastasis. Cell 118: 277-279, 2004.

51. Yao D, Dai C and Peng S: Mechanism of the mesenchymal-epithelial transition and its relationship with metastatic tumor formation. Mol Cancer Res 9: 1608-1620, 2011.

52. Swanson WF, Roth TL and Wildt DE: In vivo embryogenesis, embryo migration, and embryonic mortality in the domestic cat. Biol Reprod 51: 452-464, 1994.

53. Lamalice L, Le Boeuf $\mathrm{F}$ and Huot J: Endothelial cell migration during angiogenesis. Circ Res 100: 782-794, 2007.

54. Luster AD, Alon R and von Andrian UH: Immune cell migration in inflammation: Present and future therapeutic targets. Nat Immunol 6: 1182-1190, 2005.

55. Friedl P and Alexander S: Cancer invasion and the microenvironment: Plasticity and reciprocity. Cell 147: 992-1009, 2011.

56. Friedl $\mathrm{P}$ and Wolf $\mathrm{K}$ : Tumour-cell invasion and migration: Diversity and escape mechanisms. Nat Rev Cancer 3: 362-374, 2003. 